\title{
Estrategias basadas en el aprendizaje electrónico móvil para el desarrollo de las habilidades de escritura en el idioma inglés
}

\section{Strategies based on m- learning for the english writing skills development}

Mayra Elizabeth Alpusig Granja. ${ }^{1}$, Cristhian Andrés Villafuerte Haro. ${ }^{2}$ \& Silvia Catalina Villacís Torres. ${ }^{3}$

\begin{abstract}
.
The purpose of this article is to analyze the use of mobile applications in the English language teaching process, mainly in the development of the writing ability in English. Mobile learning (m learning) helps the development from an innovative perspective, the practice of the English language, generating a students' motivation to learn to write from new technologies so the research emphasizes the need for teachers to the University of the Armed Forces ESPE, know, master and use the range of mobile applications that can facilitate the teaching of this productive skill in the English language, through collaborative learning and with the use of ICT, which enrich the teaching-learning process in addition to generating a greater motivation in students. The article deals with the conceptual theoretical content of the fundamental categories such as m learning, mobile applications and the contribution of learning theories. In the same way, the analysis and interpretation of results is carried out, from the application of the instruments in the population and selected sample, from the descriptive statistics, in this case, the result of the application of surveys to students and teachers. Finally, a set of strategies for the development of the ability to write in English language from different mobile applications are proposed. The present research supports the importance of the use of ICT as innovative teaching resources that respond to the needs in the field of knowledge and practice of students.
\end{abstract}

Keywords: Strategies, competences, diagnosis, $\mathrm{m}$ - learning.

\footnotetext{
${ }^{1}$ Instituto Superior Tecnológico Cotopaxi, Cotopaxi, Ecuador, mealpusigg@istx.edu.ec

${ }^{2}$ Instituto Superior Tecnológico Cotopaxi, Cotopaxi, Ecuador, cavillafuerteh@istx.edu.ec

${ }^{3}$ Instituto Superior Tecnológico Cotopaxi, Cotopaxi, Ecuador, scvillacíst@istx.edu.ec
} 


\section{Resumen.}

El propósito de este artículo es analizar la utilización de aplicaciones móviles en el proceso de enseñanza aprendizaje del idioma inglés, principalmente en el desarrollo de la destreza de la escritura en inglés. El aprendizaje electrónico móvil (m learning) beneficia el desarrollo desde una perspectiva innovadora, en la práctica del idioma inglés, generando una motivación en los estudiantes para aprender a escribir desde las nuevas tecnologías por lo que la investigación hace énfasis en la necesidad de los docentes de la Universidad de las Fuerzas Armadas ESPE, conozcan, dominen y utilicen la gama de aplicaciones móviles que facilitan la enseñanza de esta habilidad productiva en el idioma inglés, a través del aprendizaje colaborativo y con la utilización de las TIC, que enriquecen el proceso de enseñanza aprendizaje además de generar una alta motivación en el estudiante. El presente artículo trata el contenido teórico conceptual tales como m learning, aplicaciones móviles y el aporte de las teorías del aprendizaje. Se realiza el análisis e interpretación de resultados, con la aplicación de los instrumentos a la población y muestra seleccionada, a partir de las estadísticas descriptivas, es decir el resultado de la aplicación de encuestas a estudiantes y docentes. En último lugar, se proponen un grupo de estrategias para el desarrollo de la habilidad de escritura en idioma inglés desde diferentes aplicaciones móviles. La investigación mantiene la importancia de la utilización y aplicación de las TIC como recursos didácticos innovadores respondiendo en sí a las necesidades en el campo del conocimiento y la práctica de los dicentes.

Palabras clave: $\mathrm{M}$ - learning, diagnóstico, estrategias, competencias.

\section{Introducción.}

La En la actualidad la tecnología móvil ha venido formando parte de las diversas actividades del ser humano convirtiéndose así en parte de la vida cotidiana de un considerable número de usuarios del internet, donde ofrece una gran variedad de posibilidades por lo que el aprendizaje y la capacitación se desarrollan de manera interesante e innovadora. En este sentido surgen interrogantes en torno a ¿por qué no integrar estos dispositivos móviles como teléfonos móviles, tabletas, Pocket PC, al proceso educativo para convertirlos en una herramienta útil e ingeniosa.

El Mobile Learning (m-learning) define prácticas que hacen provecho de los dispositivos móviles y de las tecnologías inalámbricas de transferencia de datos para favorecer y extender el alcance de los procesos de enseñanza y aprendizaje. Pardo (2010) El sistema educativo está incorporando intensivamente las nuevas tecnologías disponibles de la comunicación para apoyar el proceso de enseñanza-aprendizaje en sus diferentes modalidades y aspectos basados en el uso exponencial de Internet. Este grupo de metodologías y estrategias serán enfocadas a mejorar el sistema de enseñanza aprendizaje de las habilidades de escritura en los estudiantes del programa de Suficiencia en Inglés nivel intermedio de la UGT - ESPE de la Universidad de Fuerzas Armadas. 
Las Instituciones de Educación Superior están continuamente buscando formas innovadoras con las que buscan mejorar las experiencias de aprendizaje. La sección de Lenguas de la UGT no es la excepción, por ello pretende dar solución a un problema que actualmente está produciendo efectos negativos en este proceso como es la falta de aplicación de herramientas tecnológicas y el uso de dispositivos móviles en el desarrollo de las habilidades de escritura de los estudiantes de nivel intermedio. Esto ha provocado que los estudiantes no encuentren una motivación necesaria para despertar su interés al momento de adquirir un segundo idioma, encontrando por su parte un proceso monótono y bajo la aplicación de metodologías tradicionales.

Una de las principales causas que genera este problema es el poco conocimiento y manejo de gramática y vocabulario que los estudiantes poseen debido a la aplicación de metodologías tradicionales por parte de los docentes quienes únicamente se basan en actividades que no consiguen despertar el interés de los estudiantes.

Es evidente observar la escasa motivación que los docentes despiertan en los estudiantes a través de actividades que únicamente producen un aprendizaje poco efectivo, si se considera que no poseen conocimientos suficientes sobre las nuevas tecnologías y su aplicación en el proceso de aprendizaje.

Entre los efectos causados están el deficiente desarrollo de las habilidades de escritura en los estudiantes, quienes han demostrado problemas para emitir composiciones o la emisión de mensajes claros a sus receptores.

La aplicación y uso de la tecnología en la educación es de gran importancia debido al rápido desarrollo de la tecnología móvil y los estudiantes de educación superior quienes poseen acceso directo a internet, han tenido oportunidades para adherirse a métodos de comunicación, oportunidades para el aprendizaje colaborativo, acceso a aprendizajes, acceso a recursos de información entre otros. La innovación en celulares y otros dispositivos permite a los estudiantes tener acceso móvil para e mails académicos, bibliotecas virtuales, videos, cursos de capacitación, y la colaboración para el desarrollo y ejecución de proyectos.

Actualmente, los retos de la Educación Superior son cada día más exigentes, y para mejorar el perfil profesional las nuevas leyes de la Educación Superior Ecuatoriana exigen a todo estudiante obtener una suficiencia en el Idioma Inglés. La situación actual es preocupante a causa de que la mayoría de estudiantes no están en la capacidad de comunicarse de manera efectiva debido a que no han desarrollado y potencializado sus habilidades del idioma eficientemente.

En el Ecuador el aprendizaje electrónico móvil está contribuyendo a la educación en todos los niveles, ya que esta es la oportunidad para muchas personas en el crecimiento profesional y personal. También los procesos pedagógicos en la educación están siendo innovados a través de la tecnología en todas las instituciones educativas debido a que el mundo se va involucrando cada vez más en la nueva era de la tecnología. 
En la Sección de Lenguas de la UGT - ESPE la educación del inglés necesita ser innovado debido a que muchas debilidades han sido detectadas y estas necesitan de una inmediata solución. Los estudiantes de la Suficiencia en inglés han evidenciado problemas en el desarrollo de las habilidades de escritura y no se encuentran en la capacidad de transmitir mensajes claros y completos. El aprendizaje electrónico móvil ayudará a cambiar los enfoques de enseñanza tradicionales en métodos más modernos. Los dispositivos móviles conjuntamente a otras formas de tecnologías basadas en las herramientas de educación han establecido su potencial en la enseñanza de un idioma. Es así como la enseñanza del inglés se ha convertido en la vía más atractiva de aprendizaje con dispositivos móviles.

Con la implementación de este proyecto los beneficiarios directos serán los estudiantes de la Sección de Lenguas de la UGT - ESPE ya que mejorarán sus habilidades de escritura a través del aprendizaje electrónico móvil. La Institución será otro de los beneficiarios de este proyecto de investigación ya que tendrá la oportunidad de implementar nuevas e innovadoras estrategias de aprendizaje para la enseñanza aprendizaje de un segundo idioma a través del aprendizaje electrónico móvil.

Lo docentes de inglés son beneficiarios también porque podrán apoyar sus procesos educativos a través de la tecnología móvil aplicando estrategias que motive a sus estudiantes a un aprendizaje significativo.

Como beneficiario indirecto de este proyecto está la comunidad ya que podrán contar con profesionales calificados y competentes para la resolución de problemas sociales a través de propuestas efectivas.

Este proyecto es factible ya que se cuenta con el apoyo de las autoridades de la Institución así como de los docentes que integran la Sección de Lenguas de la UGT - ESPE.

Desde lo antes expuesto, la finalidad del presente estudio es precisamente, el análisis de la utilización de aplicaciones móviles, desde el aprendizaje electrónico móvil (m learning) con la finalidad de establecer estrategias para el desarrollo de habilidades de escritura en idioma inglés en los estudiantes de la Unidad de Tecnologías de la Universidad de las Fuerzas Armadas, que requieren de nuevas motivaciones, estrategias dinámicas para el aprendizaje del idioma y su práctica sistémica.

Es evidente la necesidad de fortalecer estrategias para el desarrollo de la habilidad de escritura en idioma inglés desde diferentes aplicaciones móviles. Sus resultados afirman que la creación de estrategias para el buen desarrollo de la redacción en inglés debe estar relacionado a la selección de actividades pedagógicas significativas con el propósito de lograr mejores resultados mediante la aplicación de estrategias dinámicas que se focalicen en alcanzar un aprendizaje significativo, desde las nuevas tecnologías y en este caso, desde las aplicaciones móviles. Investigadores de la Universidad de Málaga en el pasado año Moreno (2016), proponen algunas aplicaciones para la enseñanza de idiomas, a partir de lo cual se seleccionan y se propone un análisis por la autora de la presente investigación, expuesto en la Tabla 1: 
Tabla 1. Aplicaciones para enseñanza de idioma

\begin{tabular}{|c|c|c|}
\hline Aplicaciones & Caracterización & $\begin{array}{c}\text { Dirección } \\
\text { web/url }\end{array}$ \\
\hline Duolingo & $\begin{array}{l}\text { Es una aplicación que posibilita el aprendizaje de idiomas desde } \\
\text { ejercicios que se encuentran disponibles para smartphone o tablet, } \\
\text { así como para PC. Requiere de conexión a internet, ya que es } \\
\text { necesaria para el desarrollo de los ejercicios, así como para llevar } \\
\text { el seguimiento de los cursos que se realizan. Está estructurada por } \\
\text { bloques temáticos y niveles, desde el nivel básico hasta el } \\
\text { avanzado. }\end{array}$ & (Duolingo, 2017) \\
\hline Busuu & $\begin{array}{l}\text { Esta aplicación está organizada por niveles y temas, donde el } \\
\text { alumno estudia aspectos referidos a vocabulario, gramática, } \\
\text { fonéticos (pronunciación) y realiza ejercicios al final de cada } \\
\text { tema. }\end{array}$ & \\
\hline Bitstrips & $\begin{array}{l}\text { Aplicación de facebook para crear avatares que se pueden incluir } \\
\text { en multitud de escenas de viñetas que representan diferentes } \\
\text { contextos de la vida diaria del usuario, permitiendo la interacción } \\
\text { con avatares de amigos que tengan instalada la aplicación en } \\
\text { facebook. }\end{array}$ & $\begin{array}{l}\text { (Google play, } \\
\text { 2017) }\end{array}$ \\
\hline & $\begin{array}{l}\text { Es una aplicación gratuita de tarjetas flash incluyendo juegos para } \\
\text { el aprendizaje de nuevas palabras, la gramática y fonética. Ofrece }\end{array}$ & \\
\hline $\begin{array}{l}\text { Juega y aprende } \\
\text { idiomas }\end{array}$ & $\begin{array}{l}8 \text { temas gratuitos: los animales, la comida, las verduras, las frutas, } \\
\text { las cosas, los números, las formas y los colores. Cada bloque } \\
\text { temático contiene de } 15 \text { a } 30 \text { imágenes y se presenta en } 23 \\
\text { idiomas. Incluye cuatro modos de aprendizaje: tarjetas flash, } \\
\text { acertijo de palabras con diferentes niveles de dificultad, juego de } \\
\text { memoria y puzzle de letras mezcladas para aprender el alfabeto y } \\
\text { la ortografía. }\end{array}$ & $\begin{array}{l}\text { https://play.googl } \\
\text { e.com/store/apps/ } \\
\text { details?id=mobi. } \\
\text { playlearn.langua } \\
\text { ges\&hl=esFun }\end{array}$ \\
\hline Wlingua & $\begin{array}{l}\text { Esta aplicación constituye la plataforma de un curso de inglés que } \\
\text { consta de } 4 \text { niveles de dificultad, cada uno dividido en sus } \\
\text { correspondientes lecciones, contando con un total de } 600 \\
\text { unidades. El curso comprende los niveles A1, A2, B1 y B2, lo que } \\
\text { corresponde a los niveles Principiante e Intermedio, que son los } \\
\text { que cubre este curso. No solo se instruye en vocabulario, sino que } \\
\text { también tenemos unidades dedicadas a gramática y fonética. }\end{array}$ & (Wlingua, 2017) \\
\hline Layar & $\begin{array}{l}\text { Es una aplicación móvil para escanear aquellos elementos } \\
\text { (objetos, imágenes, páginas de libros) que hayan sido aumentados } \\
\text { empleando la aplicación web Layar Creator, a través de la cual, } \\
\text { podemos añadir información virtual complementaria (carrusel de } \\
\text { imágenes, vídeos, música, botones de acceso directo a cada perfil } \\
\text { en Twitter, en Facebook, para que puedan seguirnos en Twitter, } \\
\text { para hacer un Like, para compartir, enviar un correo) que se } \\
\text { superpone a la realidad que ha sido editada y aumentada en la } \\
\text { plataforma de Layar Creator }\end{array}$ & $\begin{array}{l}\text { (Blippar Group, } \\
\text { 2017) }\end{array}$ \\
\hline
\end{tabular}

Fuente: Investigación Documental.

De acuerdo a este cuadro de niveles, la educación superior ecuatoriana, desea ajustarse a estos estándares para alcanzar un nivel eficiente en la enseñanza del idioma inglés. Es así que la 
UGT-ESPE, ha venido llevando un proceso enfocado a que sus estudiantes obtengan el nivel apropiado de Idioma.

Si se refiere al nivel Intermedio en la cual se realizará la presente investigación, se ubica en un nivel B2, donde el estudiante es capaz de entender las ideas principales de textos complejos que traten de temas tanto concretos como abstractos, incluso si son de carácter técnico siempre que estén dentro de su campo de especialización. Puede relacionarse con hablantes nativos con un grado suficiente de fluidez y naturalidad de modo que la comunicación se realice sin esfuerzo por parte de ninguno de los interlocutores. Puede producir textos claros y detallados sobre temas diversos, así como defender un punto de vista sobre temas generales indicando los pros y los contras de las distintas opciones.

En cuanto a la habilidad de escritura a la cual se hace referencia, y constituye el objetivo de la presente investigación, el estudiante debe ser capaz de escribir textos claros y detallados sobre una amplia serie de temas relacionados con sus intereses. Puede escribir redacciones o informes transmitiendo información o proponiendo motivos que apoyen o refuten un punto de vista concreto. Sabe escribir cartas que destacan la importancia que le da a determinados hechos y experiencias.

\section{Desarrollo de habilidades de escritura en inglés.}

Una de las habilidades menos desarrolladas es la escritura y se hace indispensable que los docentes indaguen las estrategias para crear en los estudiantes una comunicación eficiente. Según, Matías (2012)

La escritura es la expresión natural de la reflexión que hacen los estudiantes sobre sus experiencias auditivas, orales y de lectura en una segunda lengua. Cuando los estudiantes escriben libremente, sin centrar su atención en los errores gramaticales que puedan cometer, desarrollan más confianza y sentido de poder en ese idioma. Esto causa un efecto que ninguna otra habilidad puede producir hasta que están bien entrenados en sus estudios de idiomas.

La producción es parte de las habilidades de la comunicación escrita, la cual expresa entonces, ideas y pensamientos a través de símbolos gramaticalmente estructurados llamados letras, en conclusión, la escritura es parte de la Lingüística Aplicada.

A pesar de lo anteriormente expuesto, los estudiantes no son muy motivados para escribir, además de en muchos casos, no desarrollan el proceso de enseñanza aprendizaje a través del trabajo colaborativo.

Por el contrario, esta habilidad es esencial para adquirir nuevos conocimientos como es en el caso del aprendizaje de un segundo idioma. Si los estudiantes de un segundo idioma, mantienen niveles bajos en la producción escrita podrán perder valiosas oportunidades internacionales las cuales buscan personas con amplio perfil profesional capaz de redactar textos en inglés y de desarrollar opiniones críticas en este idioma. 


\section{Materiales y Métodos.}

Como se ha mencionado con anterioridad, la presente investigación tiene como Objetivo General, aplicar las Tecnologías de Información y Comunicación TIC, en el proceso de enseñanza aprendizaje del Idioma Inglés a través de un conjunto de estrategias innovadoras basadas en el aprendizaje electrónico móvil para el desarrollo efectivo de las habilidades de escritura de los estudiantes de nivel intermedio.

Lo antes expuesto evidencia que la investigación corresponde a un proyecto de desarrollo por cuanto está encaminada a solucionar problemas prácticos por medio de una propuesta.

De acuerdo al origen de la investigación se dice que es de tipo cuantitativa y cualitativa, si se tiene en cuenta que la metodología cualitativa permitió realizar inferencias, valoraciones subjetivas en torno a los resultados de investigación, mientras que la metodología cuantitativa, permitió establecer los análisis porcentuales y la estadística descriptiva. En correspondencia a los objetivos de la investigación, constituye un estudio descriptivo / explicativo.

El punto de partida de la investigación fue la revisión bibliográfica anteriormente mencionada acerca del tema, planteamiento y formulación del problema, objetivos, interrogantes, caracterización de la población y selección de la muestra de estudio, elaboración de instrumentos, estudio de campo, procesamiento de datos, análisis de datos, conclusiones y recomendaciones.

Para la conformación del estudio y trabajo de campo, se estableció una muestra representativa de 120 estudiantes.

Como instrumento de medición, se seleccionó y aplicó una encuesta que permitió medir el nivel de aplicación de las aplicaciones móviles en el aprendizaje del idioma inglés y la motivación por aprender desde nuevas estrategias innovadoras; además se aplicó un cuestionario realizado en la totalidad de los casos, a 5 docentes de la Sección de Lenguas de la UGT en el período académico octubre 2016 a marzo 2017, para contar con una información válida y confiable.

El análisis e interpretación de resultados, se realizó en el Programa Estadístico SPSS, a partir del cual se obtuvieron estadísticas descriptivas sobre el conjunto de datos, pudiendo establecer valoraciones generales y por cada uno de los ítems.

\section{Resultados y Discusión.}

El análisis e interpretación de resultados, establece aspectos que pueden ser sometidos a análisis, como se muestra a continuación: 
Tabla 2. Indicadores Principales. Resumen de la Encuesta aplicada a los estudiantes:

\begin{tabular}{cc}
\hline $\begin{array}{c}\text { ¿Conoces Apps (aplicaciones móviles) } \\
\text { innovadoras para aprender el idioma } \\
\text { inglés? }\end{array}$ & $\mathrm{Si}(64.3 \%)$ \\
$\mathrm{No}(35.7 \%)$ \\
\hline $\begin{array}{c}\text { ¿Usas algún dispositivo móvil en el salón } \\
\text { de clases para practicar ejercicios acorde } \\
\text { al tema enseñado, en inglés? }\end{array}$ & $\mathrm{Si}(46.4 \%)$ \\
\hline Frecuencia_Utilización_Apps & $\mathrm{No}(53.6 \%)$ \\
& No utilizo (34.8\%) \\
& Una a dos veces por semana (35.7\%) \\
& Más doces por semana (16.1\%) \\
\hline
\end{tabular}

Fuente: Elaboración propia.

Según los resultados que se muestran en la tabla anterior, la mayoría de los estudiantes encuestados, el 64,3 \% que representa la mayoría afirma que posee conocimiento sobre las aplicaciones móviles para el proceso de enseñanza aprendizaje de inglés, lo que es un aspecto favorable para la investigación, si se considera que tienen conocimientos previos sobre dichas aplicaciones. La mayoría de los estudiantes encuestados, el 53,6 \% que representa la mayoría, afirma que no utiliza dispositivos móviles en el salón de clases para practicar ejercicios acorde al tema enseñado por el docente, en la materia de inglés, siendo necesario fomentar entre docentes y estudiantes, la necesidad de utilizar estas herramientas para la enseñanza de los estudiantes, que sea más creativa e innovadora, aprovechando que poseen conocimiento sobre las aplicaciones móviles mencionado con anterioridad.

Los estudiantes afirman que utilizan de una a dos veces mayormente las aplicaciones móviles en el proceso de enseñanza aprendizaje de inglés, según el criterio del 35,7 \% de los encuestados, que representan a la mayoría, mientras que el 34,8 \% afirma que no utiliza, lo que evidencia que es necesario implementar y fomentar el uso de aplicaciones móviles para la enseñanza de inglés a partir de la capacitación y formación para que los docentes puedan familiarizarse con las nuevas tecnologías.

Los resultados anteriores permiten argumentar la necesidad de generar situaciones y entornos de aprendizaje para el desarrollo de habilidades en el idioma inglés, desde nuevas tecnologías innovadoras e interesantes para los estudiantes.

1. Los estudiantes encuestados, el $64,3 \%$ que representa la mayoría afirma que posee conocimientos sobre las aplicaciones móviles para el proceso de enseñanza aprendizaje de inglés, lo que es un aspecto favorable para la investigación, si se considera que tienen conocimientos previos sobre dichas aplicaciones.

2. El 53,6 \% que representa la mayoría, afirma que no utiliza dispositivos móviles en el salón de clases para practicar ejercicios acordes al tema enseñado por el docente, en la materia de inglés, siendo necesario fomentar entre docentes y estudiantes, la necesidad 
de utilizar estas herramientas para la enseñanza de los estudiantes, que sea más creativa e innovadora.

3. Los estudiantes afirman que utilizan de una a dos veces mayormente las aplicaciones móviles en el proceso de enseñanza aprendizaje de inglés, según el criterio del 35,7 \% de los encuestados, que representan a la mayoría.

4. El 34,8\% afirma que no utiliza, lo que evidencia que es necesario implementar y fomentar el uso de aplicaciones móviles para la enseñanza de inglés a partir de la capacitación y formación para que los docentes puedan familiarizarse con las nuevas tecnologías.

5. La mayoría de estudiantes no tienen instalado en sus dispositivos, aplicaciones que facilitan el aprendizaje de inglés sobre todo la habilidad writing, los cuales representan el $76,8 \%$ de los encuestados, que, según sus criterios, mayormente no poseen estas aplicaciones en el celular por falta de orientación, por desconocimiento, así como los docentes que no incentivan y orientan para el uso de las aplicaciones.

6. La motivación por aprender inglés a través de aplicaciones móviles no es significativamente alta según el criterio del 57,1 \% de encuestados, que afirman que solo a veces se sienten motivados, lo que evidencia que falta trabajo por parte del docente como guías y facilitadores para la integración de nuevas tecnologías al aprendizaje.

7. La mayoría de estudiantes, el $65,2 \%$ de encuestados, afirman que solo a veces hacen un registro de avance sobre los temas tratados en clase y refuerzan el conocimiento adquirido en clase practicando con las aplicaciones móviles, siendo importante el trabajo sistematizado, de seguimiento y orientación del docente hacia los estudiantes, que genere un interés y motivación por el autoaprendizaje a partir de aplicaciones.

8. La mayoría de estudiantes, el $66,1 \%$ de encuestados, afirman que no poseen aplicaciones necesarias en su teléfono celular para practicar la habilidad de escritura (Writing) en inglés, si se considera que desconocen del tema, que mayormente no utilizan las aplicaciones y que no tienen supervisión por parte de los docentes.

9. El acceso a la tecnología es libre, es autorizado y pueden manejar las TIC, siempre y cuando forme parte del proceso de enseñanza aprendizaje y enfocado a la construcción del conocimiento, según el criterio del 53,6 \% de encuestados, sin embargo, por respuestas mencionadas con anterioridad, se puede afirmar que a pesar de las facilidades y soportes tecnológicos no se utilizan las nuevas aplicaciones móviles como recursos didácticos para el aprendizaje de inglés.

10. A pesar de no utilizar con frecuencia significativa las aplicaciones móviles en la enseñanza del idioma inglés, los estudiantes tienen conocimiento y entienden acerca de los beneficios que brinda una aplicación móvil en el aprendizaje del idioma inglés, por 
lo que el $92 \%$ responde afirmativamente sobre su concepción y percepción de la importancia de las nuevas tecnologías para el aprendizaje.

Tabla 3. Ítems Principales. Resumen de la Investigación de Campo aplicada a docentes:

\begin{tabular}{l}
\hline ¿Presenta opciones no tradicionales de \\
aprendizaje que guíen al uso de las \\
$\begin{array}{l}\text { nuevas formas de aprendizaje como M- } \\
\text { learning (Aprendizaje móvil)? }\end{array} \quad$ Rara Vez $(40 \%)$ \\
\end{tabular}

¿De las siguientes nuevas tecnologías que aportan a la enseñanza aprendizaje, cuál considera la más factible a implementar para la enseñanza del idioma inglés?

Plataformas virtuales $(60 \%)$

Aplicaciones móviles $(20 \%)$

CD Interactivos (20\%)

\begin{tabular}{lc}
\hline ¿Ha recibido en los últimos tres años, & $\mathrm{Si}(80 \%)$ \\
capacitaciones en el manejo de las TIC? & No $(20 \%)$
\end{tabular}

Fuente: Elaboración propia

Es en este sentido, que resulta fundamental la identificación de requerimientos y necesidades de los docentes como punto de partida, para la búsqueda de alternativas de solución que posibilite un cambio, considerando que existen numerosas falencias en cuanto a cómo desarrollar competencias en idioma inglés, así como la falta de conocimientos para el diseño de estrategias orientadas a potenciar la habilidad de writing; por lo que se hace necesario mejorar el proceso de enseñanza aprendizaje y apuntar al manejo adecuado de nuevos recursos didácticos. El $80 \%$ reconoce que ha recibido capacitaciones en los últimos tres años aspecto favorable que tributa directamente, a la calidad del proceso de enseñanza aprendizaje.

El $40 \%$ presenta opciones no tradicionales de aprendizaje que guían al uso de las nuevas formas de aprendizaje como M- learning (Aprendizaje móvil), con una frecuencia de a veces y solo un $20 \%$ afirma que siempre guía a los estudiantes hacia estas formas de aprendizaje. En este sentido, se requiere por parte del docente un trabajo sistematizado en los estudiantes para que adopten nuevas formas de aprendizaje.

El $60 \%$ de encuestados, afirma que mayormente es más factible el uso de plataformas virtuales para la enseñanza del idioma inglés y solo un $20 \%$ reconoce a las aplicaciones móviles, sin embargo, desde el punto de vista del estudiante, las aplicaciones móviles podrían ser más motivadoras y accesibles.

1. El $40 \%$ de docentes encuestados promueve el proceso enseñanza aprendizaje del idioma inglés con el uso de dispositivos móviles, para aprender a través de esta herramienta, con una frecuencia de a veces mientras que el $40 \%$ promueve este tipo de enseñanza casi siempre y solo un $20 \%$ siempre. Los resultados permiten afirmar que 
se requiere capacitar a los docentes para el uso de las nuevas tecnologías y medios de aprendizaje.

2. El $40 \%$ presenta opciones no tradicionales de aprendizaje que guían al uso de las nuevas formas de aprendizaje como M- learning (Aprendizaje móvil), con una frecuencia de a veces y solo un $20 \%$ afirma que siempre guía a los estudiantes hacia estas formas de aprendizaje. En este sentido, se requiere por parte del docente un trabajo sistematizado en los estudiantes para que adopten nuevas formas de aprendizaje.

3. El $80 \%$ reconoce que ha recibido capacitaciones en los últimos tres años aspecto favorable que tributa directamente, a la calidad del proceso de enseñanza aprendizaje. Aun así, es insuficiente la capacitación para implementar el aprendizaje a través de dispositivos móviles.

4. El $60 \%$ de los docentes afirma que casi siempre la aplicación dispositivos móviles en la enseñanza del Idioma Inglés, involucra a los estudiantes en un aprendizaje colaborativo, y solo un $20 \%$, afirma que siempre puede involucrarlos en un aprendizaje colaborativo por la interacción e intercambio, percepción que debería de ser una tendencia en la totalidad de docentes.

5. El $100 \%$ de los docentes afirma que es de utilidad la aplicación de Blogs Académicos, Correos electrónicos, Foros, dispositivos móviles, como forma de ayuda para mejorar la comunicación escrita de sus estudiantes, lo que corrobora que existe una apertura por parte de los docentes, a utilizar el aprendizaje $\mathrm{m}$ - learning.

6. El $60 \%$ de los docentes afirma que mayormente utilizaría como técnicas participativas para desarrollar las habilidades de escritura en sus estudiantes, a través de dispositivos móviles, la elaboración de postales y cartas, las redes sociales y blogs académicos, lo que evidencia que a través de los dispositivos móviles es factible desarrollar habilidades para escribir en inglés.

Es importante el desarrollo de la presente Propuesta, en la medida que los docentes y estudiantes deben mejorar las estrategias, métodos, técnicas que se utilizan actualmente para el desarrollo de habilidades en el aprendizaje del idioma inglés, con el fin de contribuir a un aprendizaje más autónomo, creativo, eficiente y competitivo. Los estudiantes con una base excelente en habilidades para escuchar, hablar, escribir, tendrían una formación acorde a los requerimientos de los nuevos contextos; que desarrollen sus habilidades con estrategias metodológicas adecuadas y ajustadas a su realidad social y cultural. Se trata de mejorar el aprendizaje innovando las Estrategias Metodológicas empleadas por los docentes, considerando que, en muchos casos, no existen recursos didácticos apropiados para desarrollar eficientemente los procesos de enseñanza - aprendizaje en el idioma inglés y desarrollar las habilidades para escribir, desde la incorporación de las TIC en las situaciones de aprendizaje.

El presente trabajo se fundamentó en determinar el uso de aplicaciones móviles y el aporte que tienen en el proceso de enseñanza aprendizaje del idioma inglés para los docentes y estudiantes 
con la finalidad de complementar y fortalecer las destrezas de los estudiantes que forman parte de la Sección Lenguas de la UGT - ESPE, ubicada en el cantón Latacunga.

Del análisis de resultados se puede concluir que las estrategias propuestas que deben utilizarse, basadas en el aprendizaje electrónico móvil para el desarrollo de habilidades de escritura a través del aprendizaje colaborativo para los estudiantes de inglés Nivel Intermedio de la Sección de Lenguas de la UGT ESPE, son las siguientes:

Tabla 4. Aplicaciones para aprendizaje electrónico móvil.

\begin{tabular}{|c|c|c|}
\hline Apps & Descripción & Actividades \\
\hline $\begin{array}{l}\text { Write and } \\
\text { Improve }\end{array}$ & $\begin{array}{l}\text { Esta aplicación es una herramienta digital } \\
\text { que permitirá a los estudiantes de inglés } \\
\text { conocer los errores sobre el texto que han } \\
\text { redactado y sugerir diversas maneras para } \\
\text { mejorarlo. }\end{array}$ & $\begin{array}{l}\text { Es mucho más que un corrector de texto, es una } \\
\text { herramienta centrada en la expresión escrita que } \\
\text { permitirá evolucionar en el aprendizaje del inglés. Al } \\
\text { estar basada en un sistema de prueba y error, } \\
\text { permitirá al alumno comparar cómo va mejorando su } \\
\text { nivel y la manera y ritmo en que va adquiriendo los } \\
\text { conocimientos deseados. }\end{array}$ \\
\hline Movenote & $\begin{array}{l}\text { Esta aplicación permite hacer textos, } \\
\text { mapas conceptuales, blogs }\end{array}$ & $\begin{array}{l}\text { Posibilita el desarrollo de la expresión escrita al } \\
\text { favorecer la práctica de la redacción }\end{array}$ \\
\hline $\begin{array}{c}\text { English } \\
\text { Conversation } \\
\text { Practice }\end{array}$ & $\begin{array}{l}\text { Esta aplicación dispone de audios para } \\
\text { escuchar, así como de una evaluación para } \\
\text { reforzar el conocimiento, dispone de una } \\
\text { conversación con un nativo para que el } \\
\text { estudiante pueda interactuar y finalmente } \\
\text { adquirir una pronunciación adecuada así } \\
\text { como visualizar los textos de las lecturas. }\end{array}$ & Posibilita el desarrollo de la expresión oral y escrita \\
\hline $\begin{array}{l}\text { Quiver y } \\
\text { Chromville }\end{array}$ & $\begin{array}{l}\text { Se puede trabajar el lenguaje espontáneo y } \\
\text { dirigido, el componente pragmático (uso } \\
\text { conversacional del lenguaje), a través de la } \\
\text { descripción los personajes y objetos de su } \\
\text { entorno en 3D empleando el idioma en } \\
\text { cuestión. }\end{array}$ & $\begin{array}{l}\text { Favorece la motivación y la creatividad en el } \\
\text { alumnado, se fomenta la invención de historias a } \\
\text { partir de los personajes y objetos diversos que nos } \\
\text { muestran las láminas. Desarrolla la expresión escrita. }\end{array}$ \\
\hline Layar & $\begin{array}{l}\text { Con esta aplicación se pretende escanear y } \\
\text { visualizar escenas aumentadas a partir de } \\
\text { aquellas imágenes e ilustraciones de } \\
\text { cuentos o cómics que previamente hayan } \\
\text { sido editadas añadiéndoles información } \\
\text { virtual adicional a través de la plataforma } \\
\text { web Layar Creator. }\end{array}$ & Desarrollo de la expresión oral y escrita \\
\hline
\end{tabular}

Fuente: Elaboración propia.

A partir de lo antes expuesto y para la presente investigación, se considera el M-learning, como un aprendizaje que posibilita la generación de aprendizajes significativos, desde diferentes espacios y contextos, más allá y sin circunscribirse a los límites del aula de clases, sino que complementa, favorece, los aprendizajes de manera flexible y móvil; por ende, el desarrollo de competencias a partir del aprendizaje autónomo, de las experiencias colaborativas entre 
estudiantes y docentes, siendo indispensable lograr estrategias de m-learning apropiadas y ajustadas al contexto educativo.

\section{Aplicaciones para el desarrollo de la expresión escrita.}

Para el desarrollo de la expresión escrita, existen múltiples aplicaciones relacionadas con mensajería de textos desde los dispositivos móviles. Existen aplicaciones de mensajería similares a los SMS o los MMS, que permiten el envío de texto, imágenes, sonido y video, pero de forma gratuita. De ahí que sea factible integrar a las clases de inglés este tipo de aplicaciones que favorecen la comunicación entre alumnos y docentes desde las cuales el maestro puede realizar comentarios y tutorías, recordatorio de tareas, aclaración de dudas.

Tabla 5. Aplicaciones móviles para la escritura del idioma inglés.

\begin{tabular}{|c|c|c|}
\hline Aplicaciones & Descripción & Ventajas y aportes \\
\hline Beelingo & $\begin{array}{l}\text { Esta herramienta también ofrece un groso volumen } \\
\text { de contenido: audios, prácticas de gramática, } \\
\text { vocabulario, diccionarios, juegos educativos. }\end{array}$ & $\begin{array}{l}\text { Habilidades que se practican: } \\
\text { listening, reading y grammar }\end{array}$ \\
\hline Learn English & $\begin{array}{l}\text { Es una aplicación creada por el British Council que } \\
\text { le permite estudiar inglés en Android o Iphone a } \\
\text { través de videos con los que mejora su comprensión } \\
\text { de lectura y aprende vocabulario. Además, no es } \\
\text { necesaria una conexión continua a Internet cuando } \\
\text { los episodios se descargan. }\end{array}$ & $\begin{array}{l}\text { Pronunciación, listening y } \\
\text { speaking, grammar }\end{array}$ \\
\hline BBC Skillwise & $\begin{array}{l}\text { Presenta una serie de videos con actividades } \\
\text { prácticas que enseñan diferentes técnicas para } \\
\text { mejorar nuestro inglés. }\end{array}$ & $\begin{array}{l}\text { Writing, al mostrar cómo } \\
\text { hacer un plan antes de } \\
\text { escribir un documento en } \\
\text { inglés, escribir un correo, } \\
\text { entre otros textos }\end{array}$ \\
\hline Wlingua & $\begin{array}{l}\text { Es un curso de inglés que se puede desarrollar desde } \\
\text { tu Iphone o Android. Es ideal para los principiantes, } \\
\text { que se declaran incompetentes al idioma o para } \\
\text { aquellos que necesitan mejorarlo ya que consta de } \\
\text { gran manejabilidad y una amplia guía para el } \\
\text { alumno. }\end{array}$ & $\begin{array}{l}\text { Pronunciación, listening y } \\
\text { speaking, grammar }\end{array}$ \\
\hline Plain English & $\begin{array}{l}\text { Ofrece una serie de guías en PDF relacionadas con } \\
\text { planificar y escribir un documento en inglés, } \\
\text { escribir un correo electrónico y textos. }\end{array}$ & $\begin{array}{l}\text { Writing para el aprendizaje } \\
\text { de redacción }\end{array}$ \\
\hline Cll-Writing & $\begin{array}{l}\text { Enseña la forma de redactar documentos como } \\
\text { cartas, informes, correos electrónicos, brindando la } \\
\text { oportunidad de practicar con dichos documentos en } \\
\text { la misma página. }\end{array}$ & Writing \\
\hline
\end{tabular}

Fuente: Elaboración propia.

El resultado de la aplicación de la propuesta pone en manifiesto que los saberes para el desarrollo de las habilidades de redacción, han mejorado notablemente. 
Al realizar el diagnóstico del estado inicial del grupo de estudiantes se encontró que algunos de los estudiantes no poseen competencia en writing a un nivel óptimo de aprendizaje y desarrollo.

La construcción de la propuesta pedagógica favorece la implementación de estrategias para el desarrollo de la expresión escrita. Al implementar la propuesta pedagógica se fortalece en los estudiantes las habilidades para el desarrollo de la expresión escrita.

La propuesta contribuye al mejoramiento de la redacción en idioma inglés en los estudiantes.

Es pertinente el desarrollo de actividades pedagógicas que reúnan y atraigan la curiosidad de los estudiantes, para ello el docente debe hacer más acompañamientos y orientaciones en los procesos de enseñanza aprendizaje con el propósito de lograr mejores resultados mediante la aplicación de estrategias dinámicas que se focalicen en alcanzar un aprendizaje realmente significativo.

El proceso de investigación que se desarrolla, permite que los docentes reflexionen sobre su práctica, cuáles son las estrategias que utiliza en la actualidad, si se encuentran acorde a las exigencias de los momentos actuales. Se puede definir que la expresión escrita en idioma inglés, tiene como propósito fundamental ayudar a lograr incorporar en los estudiantes, la fluidez y la comprensión de la segunda lengua, apuntando hacia la comunicación efectiva.

Las estrategias manejadas por los docentes, se sustentan en la capacitación constante, la retroalimentación con las experiencias de otros docentes, el poder participar de espacios de reflexión y debate y poder comparar, los contextos educativos.

\section{Conclusiones:}

- Los métodos de enseñanza - aprendizaje han ido evolucionando con el avance diario de la tecnología, por lo que los maestros se han visto obligados a buscar nuevas formas de incentivar al alumnado para el aprendizaje del idioma inglés y su participación activa en este proceso; considerando como alternativa, aunque no en la mayoría de los casos, las aplicaciones móviles como recurso didáctico.

- El uso de las aplicaciones móviles aporta numerosas ventajas entre las cuales sobresale mayormente el hecho de la versatilidad y portabilidad en el momento de su uso, optimizando tiempos y aportando un nuevo concepto del espacio ya no siendo necesario el aula de clases, sino un aprendizaje interactivo desde diferentes espacios y ubicaciones. El aprendizaje del idioma inglés a través de aplicaciones móviles más que una estrategia de aprendizaje se consolida como competencia necesaria y ajustada a los nuevos ritmos de aprendizaje y sin dudas, constituye un elemento importante de la llamada alfabetización del siglo XXI.

- Los dispositivos móviles no solo son parte de una visión de cambio generacional o de estructura pedagógica, significa, además, la posibilidad de vincular las TIC en el 
proceso de enseñanza aprendizaje y posibilitar que los estudiantes interactúen con estos nuevos métodos, como una nueva herramienta de aprender y reforzar el idioma. Alpusig (2017)

\section{Referencias bibliográficas:}

Blippar Group. (12 de Enero de 2017). Layar. Obtenido de https://www.layar.com/accounts/login/?next=/creator/

Duolingo. (9 de Enero de 2017). Doulingo.com.es. Obtenido de https://www.busuu.com/es/

Google play. (9 de Enero de 2017). Bitmoji. Obtenido de http://www.bistrips.com/

Matía CRM, V. M. (2012). La enseñanza de la escritura en inglés con fines médicos. Rey Cubana Hig Epidemiol, p. 258.

Moreno Noelia, L. J. (2016). Mobile learning, Gamificación y Realidad Aumentada para la enseñanza-aprendizaje de idiomas. Ijeri.

Pardo Hugo, B. M. (2010). Prototipos de Mobile Open Education: Una breve selección de casos. Revista Iberoamericana de Tecnologías del Aprendiizaje, p. 11.

Wlingua. (09 de Enero de 2017). Wlingua . Obtenido de http://www.wlingua.com/es

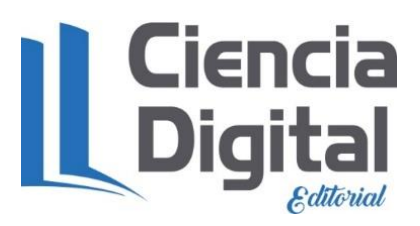




\section{PARA CITAR EL ARTÍCULO INDEXADO.}

Alpusig Granja, M. E., Villafuerte Haro, C. A., \& Villacís Torres, S. C. (2020). Estrategias basadas en el aprendizaje electrónico móvil para el desarrollo de las habilidades de escritura en el idioma inglés. Explorador Digital, 4(3), 110-125. https://doi.org/10.33262/exploradordigital.v4i3.1292

\section{Ciencia LDigital}

El artículo que se publica es de exclusiva responsabilidad de los autores y no necesariamente reflejan el pensamiento de la Revista Explorador Digital.

El artículo queda en propiedad de la revista y, por tanto, su publicación parcial y/o total en otro medio tiene que ser autorizado por el director de la Revista Explorador Digital.
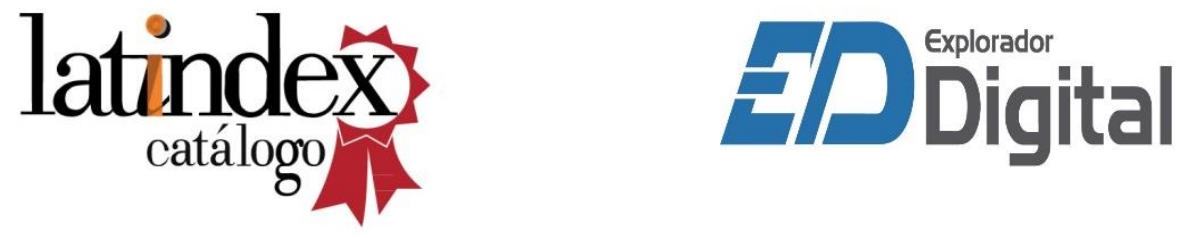